\title{
A Dinâmica das Formas Alternativas do Ensino de Química Proporcionando a Criatividade dos Alunos
}

Danielly Santos de Araújo* (Graduanda em Química na Universidade Federal de Campina Grande -

UFCG);

Tereza Neumann Vasconcelos Porto (Professora na Escola Estadual Orlando Venâncio dos Santos);

J osé Carlos Oliveira Santos (Professor na UABQ/CES na Universidade Federal de Campina Grande -

UFCG)

*E-mail: dany_200727@hotmail.com

Resumo: A educação vem passando por muitas mudanças no decorrer dos tempos, entre estas transformações estão as novas tendências de ensino conhecidas como formas alternativas de ensino, onde se trabalha de forma interdisciplinar, fazendo uma conexão com o que é ministrado em sala de aula e o cotidiano do discente. Este trabalho tem como objetivo mostrar como as duas formas de ensino caminhando juntas, a forma tradicionalista e a forma alternativa de ensino, através da temática água atrelada aos conceitos de química usando os quadrinhos e o teatro. Observou-se que os alunos entenderam os conceitos de química através das suas próprias criações nas histórias em quadrinhos, fazendo com que o processo de ensino e aprendizagem tome uma nova vertente. Apesar das barreiras enfrentadas pelos dois lados, dentro da sala de aula, essas formas alternativas incentivaram a produção de sua própria história, de forma a instigar a criatividade, a responsabilidade do aluno, trabalhando com as outras disciplinas da escola e incentivando o aluno a sempre ler.

Palavras-chave: Formas alternativas de ensino; teatro; história em quadrinhos; ensino de química.

Espaço reservado para organização do congresso. 


\section{I ntrodução}

A educação, de uma forma geral, vem passando, constantemente, por mudanças, para propiciar novas formas de ensino para os docentes e, consequentemente, as aulas serão ministradas de forma mais dinâmica, usando como base a forma tradicional de ensino de uma perspectiva alternativa. A forma como as aulas de química vêm sendo abordadas na escola, ao longo dos anos, demonstra que há uma grande necessidade de se contextualizar mais as aulas, pois as mesmas demonstram que os alunos acham monótonas e sem atrativos que prendam a sua atenção na sala. Com a falta de interesse dos discentes, os docentes acabam ficando desmotivados também com a sala de aula. Vygotsky (1998) apresenta em suas pesquisas, que o ser humano passa por dois processos de formação dos conceitos. $\mathrm{O}$ primeiro processo ocorre na fase infantil, quando a criança, em suas experiências cotidianas, desenvolve habilidades fora da escola, em convivência familiar e com outras pessoas. O segundo processo apresentado diz respeito à formação dos conceitos científicos, ocorrido na escola, sendo sistematizado por experiências de cunho científico, com maior grau de complexidade (SILVA et al, 2006).

Ao se trabalhar com formas alternativas de ensino de química, a aula deixa de ser um sacrifício e passa a ser um complemento para educação, pois quando relacionado de forma contextualizada com a sua vivência diária há uma compreensão da importância da química para além da sala de aula, tanto o ensino como a aprendizagem acaba tomando novas vertentes para ser trabalhado dentro da escola. É importante desenvolver a capacidade do estudante no sentido de que esse possa participar e tomar decisões críticas sobre os temas propostos em seu cotidiano. Precisamos observar a linguagem da Química, pois o estudante do ensino médio está se apropriando de um novo vocabulário acompanhado de novos significados. Diante da complexidade que se apresenta, a linguagem da química deve ser vista de maneira simplificada, sendo que o objetivo principal não se trata da memorização, mas da compreensão da importância do conhecimento químico e os seus princípios gerais (SILVA et al, 2013).

Ao se trabalhar com recursos de áudio visual tem que se ter muito cuidado com o que vai ser apresentado para os alunos, pois não pode fugir do assunto apresentado em sala de aula. Segundo Conde et al.(2013), o professor é mediador do conhecimento, o qual auxilia, dá suporte e estimula os alunos na construção de seus conceitos, saindo do papel de detentor do conhecimento e tornando real a capacidade de se obter e entender os fenômenos da natureza e as transformações produzidas pelo homem através do ensino, onde cada indivíduo saberá exercer seu papel de forma responsável, consciente e crítica (LIMA et al., 2011). Este processo é utilizado para auxiliar a aprendizagem do aluno de forma contextualizada, promovendo o debate dentro da sala de aula e como consequência compreender o conteúdo de forma alternativa. Os quadrinhos tem se mostrado uma forma alternativa de ensino, muito produtivo, pois ao se instigar a criatividade deles para produção textual com temáticas de química, demonstrando que os discentes têm um processo de aprendizagem interdisciplinar, pois para a criação das historias em quadrinhos ele precisa abranger outras áreas dos conhecimentos. Este trabalho tem como objetivo demonstra novas formas de ensino de química, de forma interdisciplinar, promovendo o debate dentro da sala de aula, fazendo uso de materiais audiovisuais e estimulando a criatividade dos aluno na produção textual das histórias em quadrinhos.

Segundo a LDB (1996), citado por Rosa (2012), o ensino de química deve colaborar na educação de forma a alicerçar a construção do conhecimento científico do educando, colocando-o como sujeito desse processo e não como mero espectador. Ou seja, contextualizar é dar significado aos conteúdos e torná-los possíveis de serem questionados. Trabalhar os conteúdos de maneira contextualizada facilita o processo de aprendizagem. A simples tarefa de ferver a água para preparar alimentos pode e deve estar relacionado com o conteúdo de química visto em sala de aula. O estudo da química deve estar centrado na compreensão de assuntos e não na memorização de fórmulas, regras e nomenclaturas.

\section{Metodologia}

O PIBID vem fazendo uma parceria com a Escola Estadual de Ensino Médio Orlando Venâncio dos Santos, localizada na cidade de Cuité - PB, como os alunos do ensino médio. A proposta era se trabalhar nas salas de aula, fazendo uso de formas alternativas de ensino, correlacionando o conteúdo 
de química com o cotidiano, vivenciado pelo aluno da escola. Silva et al. (2013) neste sentido, nos vemos em uma arena de lutas, pois fazer educação exige, antes de tudo, uma luta que se dá no dia a dia, que se faz, se replica e se desdobra. Esses desdobramentos se tratam da materialidade de nossa escolha metodológica, permitindo assim que os estudantes consigam compreender a relação entre o conteúdo proposto e o conteúdo social do ensino de química.

Foram apresentados vídeos que trabalhavam o tema proposto, gerando debate dentro da sala de aula, onde o aluno expunha sua opinião com relação ao conteúdo, trabalhou-se a criatividade deles através de produção de cartazes para servir de alerta sobre a problemática exposta pelo professor.

A temática que foi trabalhada pelos alunos foi a escassez de água, problema que vem sendo enfrentado em nossa região, relacionando com os conceitos de química aprendido em sala de aula como: ligações químicas, polaridade, soluções, como também conhecer um pouco da história da química através da alquimia. O professor não pode ficar aprisionado apenas no ensino tradicional, sendo necessário utilizar metodologias de ensino alternativas com recursos no qual o ele tem acesso (CONDE et al.2013). A criatividade do aluno se faz necessária quando se trabalha com produção textual no formato de histórias em quadrinhos como também na produção de peças teatrais e vídeos, sendo todas formas alternativas de ensino, trabalhando de forma interdisciplinar com o português, inglês e espanhol. Para Pinheiro et al.(2013 ), ouvir os alunos possibilita ao professor tornar-se um companheiro, gera confiança e possibilita também que a relação entre educador e educando caminhe no sentido da superação da contradição de concepções que existem entre eles (GASPARIN, 2007).

O trabalho se desenvolveu em momentos distintos como incentivar a criatividade do aluno em criar a sua própria história com base no conteúdo de química, trabalhando a temática água; incentivando o aluno a ler para desenvolver boas histórias; após a produção dos quadrinhos eram apresentados para suas turmas, ainda se fez uso de vídeos sobre a temática da falta de água, que gerou um debate produtivo nas turmas, cada uma expondo a sua opinião e a defendendo, produzindo cartazes que ficaram em exposição na escola, para servir de alerta para a falta desse bem tão precioso que é a água. Com o comprometimento dos alunos foi possível montar uma peça teatral, trabalhando a história da química através da alquimia, possibilitando ao discente conhecer um pouco mais dos químicos importantes na nossa história. A apresentação do teatro foi na feira de ciências da escola.

\section{Resultados e Discussão}

Como bem se sabe ,ensinar química tem se mostrado um desafio constante para o professor, devido a grande dificuldade de sair um pouco da forma tradicionalista de ensino. Para apresentação do conhecimento cientifico aos educando se faz necessário buscar novos caminhos para apresentação deste conhecimento, tornado a aula mais produtiva. Segundo Cunha et al. (2011) contudo observou-se que o uso de recursos didáticos alternativos possibilitou ao professor transmitir as informações com mais facilidade, além de ter proporcionado aos estudantes a compreensão dos conteúdos explicados em sala de aula. Com essa nova metodologia de ensino, verificou-se que os alunos manifestaram mais interesse e curiosidade pela disciplina de Química, isso os tornou mais participativos nas aulas, além de terem melhorado na assiduidade.

O PIBID vem trabalhando em parceria com o professor na sala de aula, procurando formas alternativas de ensino como a criação de histórias em quadrinhos (Figura 1), como seria possível trabalhar a temática " água bem precioso e fundamental para a nossa sobrevivência”, fazendo relação com os conceitos de química previamente apresentado aos educando e depois debatido em sala de aula, para formar a opinião deles com relação do que seria produzido por eles. As criações começaram com a produção e apresentação de cartazes sobre o tema água. Com base nas produções dos cartazes teve início a produção dos quadrinhos, fazendo relação entre o cotidiano com os conceitos de química, trabalhando polaridade, soluções e ligações químicas. Após vários debates na sala de aula, começaram a produção das suas próprias histórias, despertando, assim, o interesse do aluno para leitura e expondo os quadrinhos como uma forma alternativa de ensino. Pode-se dizer que, a partir da aceitação dos quadrinhos nos livros didáticos, a ideia de nocividade dos mesmos cai por terra. Embora essa linguagem, muitas vezes, seja empregada nos livros de maneira errônea, foi à entrada das historinhas nos livros didáticos que fez com que as mesmas passassem a ser vistas (até mesmo pelos mais tradicionais) como possível material educativo, uma vez que agora estavam presentes no material didático indicado para a sala de aula. (PIZARRO, 2005). 
Figura 1 - Construção de quadrinhos sobre o conceito de polaridade.

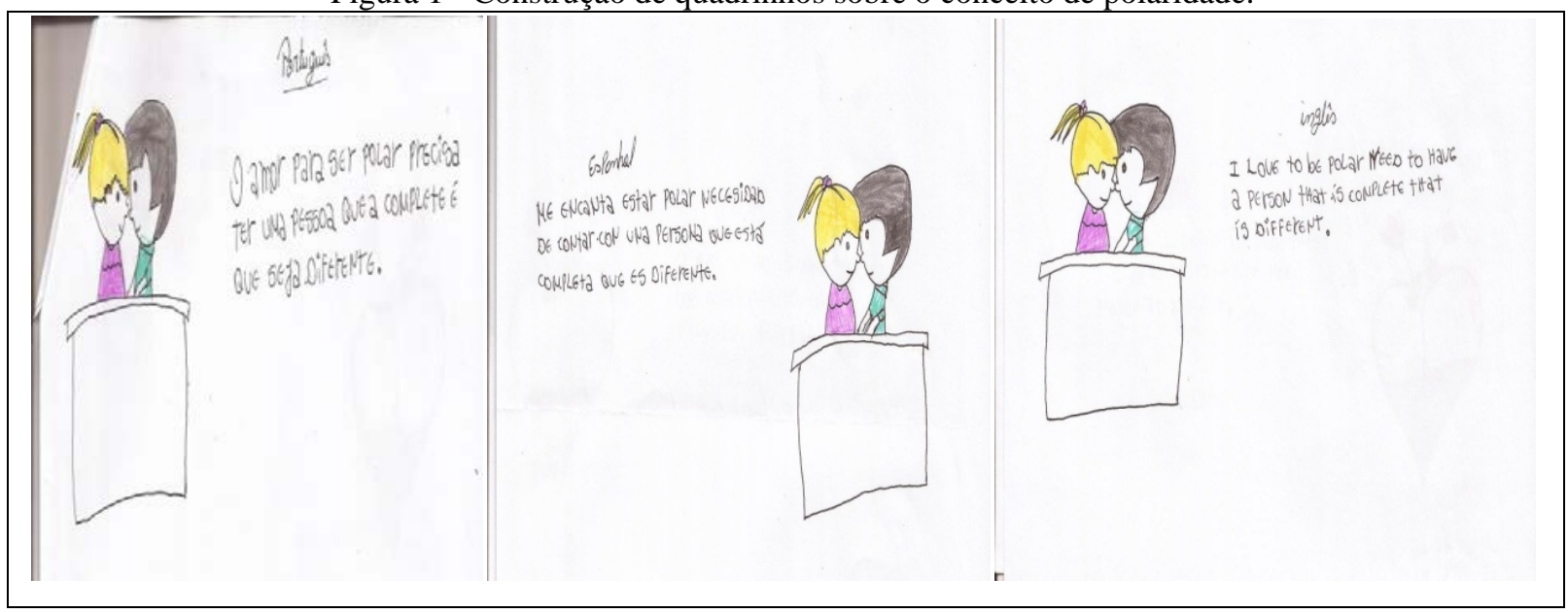

Fonte: própria pesquisa

Os discentes ficaram empolgados com a criação de as suas próprias tirinhas, pois trabalharam de forma interdisciplinar, fazendo relação com outras matérias trabalhadas na escola, após todo esse processo o trabalho deles seria demonstrado para toda a turma. Para Rosa (2012), a prática docente e um currículo escolar contextualizados devem estar pautados nas diferenças cognitivas e sócio culturais. Isso significa que o ensino de química deveria estar fundamentado a outros conteúdos, desde as séries iniciais, respeitando a forma de abordagem específica para cada série do ensino. Essa integração entre as disciplinas poderia ocorrer através do uso de temas transversais que possibilitariam a inclusão de conceitos químicos básicos para uma melhor construção do conhecimento científico nas series finais. O interesse do aluno ficou evidente durante o desenvolvimento desde projeto; a avaliação era feita de forma contínua e informal, a observação foi a forma avaliativa que se utilizou para avaliar o quanto o discente evoluiu durante o decorrer desde projeto.

Para a feira de ciências da escola foi trabalhado o conceito de química na forma de teatro (Figura 2), onde era contado um pouco sobre a história da química, através de Maria Judia e Basílio, mostrando como era a química através dos alquimistas; foi muito gratificante observar o comprometimento dos discentes neste processo, eles levaram a sério o que ia ser apresentado, ensaiaram muito, preocuparam-se com o figurino e o material pra montar o laboratório, trabalharam de forma conjunta com os pibidianos, formando um elo acadêmico forte.

Figura 2 - Forma alternativa de ensino através da arte (teatro).

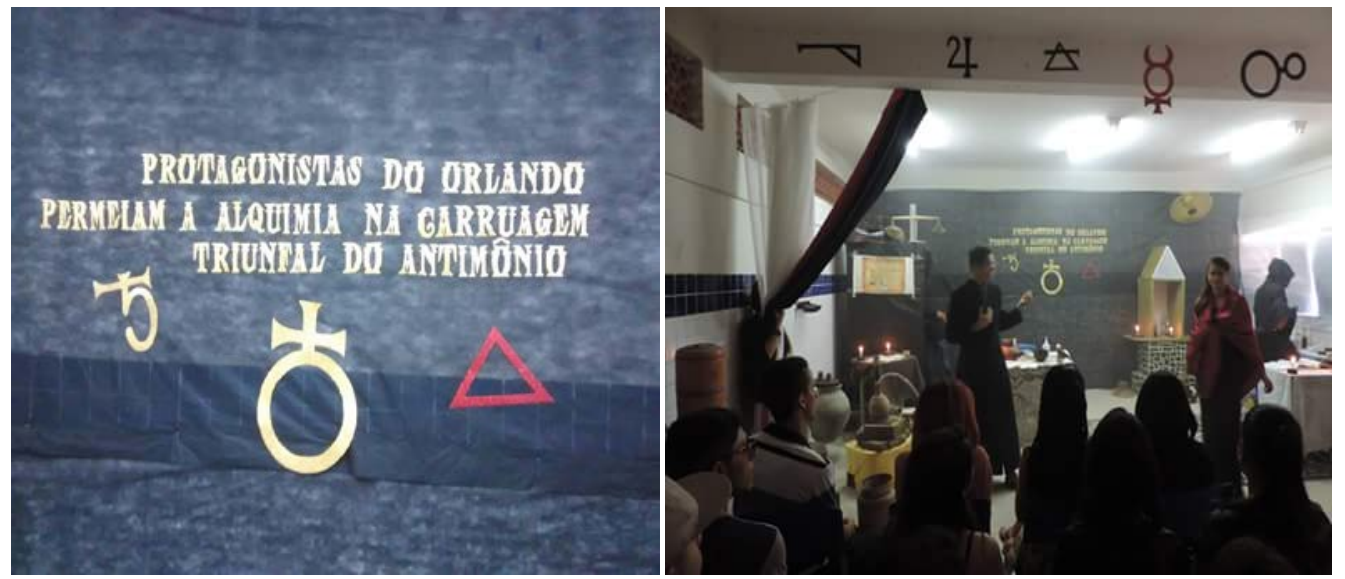

Fonte: própria pesquisa

O recurso áudio visual quando apresentado aos alunos, sempre acaba deixando a aula mais produtiva, tanto para o docente como para o discente, proporcionando momentos de interação entre a 
classe e o mestre em um debate que, no final, acaba rendendo bons cartazes para expressar a compreensão do que foi ensinado para eles; as formas alternativas de ensino andam ligadas com o tradicionalismo, para propiciar aulas mais dinâmicas, formando uma parceria entre a classe e seu docente no processo de ensino e aprendizagem (Figura 3).

Figura 3 - Trabalhando com áudio visual como forma alternativa de ensino.

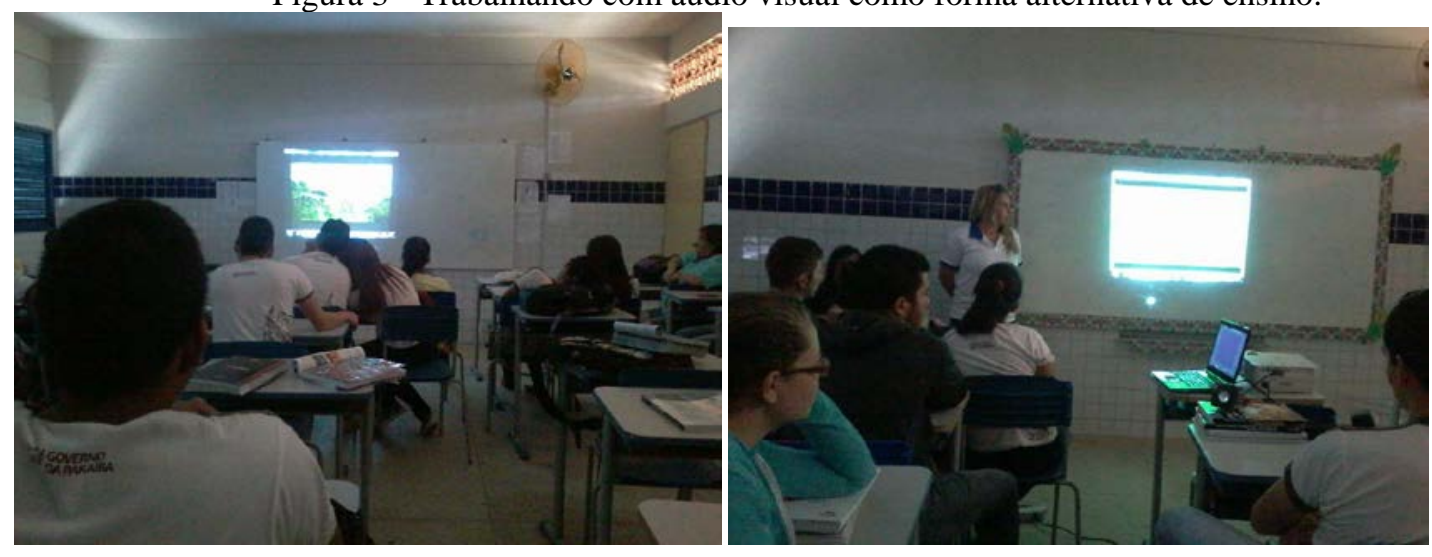

Fonte: própria pesquisa

Segundo Vigotski (2003), citado por Rosa (2012), o desenvolvimento do ser humano é fundamentado na colaboração que existe entre este e um mediador, que pode ser um educador. A ação do mediador provoca no educando o desenvolvimento de suas capacidades que por si só não seriam desenvolvidas. Essa função é chamada de zona de desenvolvimento proximal ou potencial que são as ações realizadas através de atividades mediadoras.

\section{Conclusão}

O trabalho aponta os pontos positivos que as formas alternativas de ensino vêm proporcionando aos alunos, estimulando a sua criatividade, auxiliando a trabalhar em grupo, aprendendo a serem mais responsáveis, tanto na sua vida acadêmica como na vida social. Como educadores, acreditamos que, para que haja aprendizagem, faz-se necessária a reflexão da própria ação de ensinar e refletir a própria ação, implicando mudança de prática pedagógica: mudança conceitual e atitudinal por parte do educador. Nesse sentido, o ensino de Química clama por novos significados, novos contextos, nova compreensão do mundo e do ser para o processo de formação de conceitos científicos. A temática trabalhada com os alunos foi a água, pois este bem tão preciso está escasso na nossa região, trabalhando essa temática na química fez o discente compreender o conteúdo de química como: polaridade, ligações e soluções, sendo estes conteúdos que podem ser bem explorados na temática estabelecida .

A evolução dos alunos, durante a sua própria criação, gerou bons frutos, auxiliando no processo de ensino e aprendizagem. Os alunos acabam ficando mais interessados na sala, aprendendo o conteúdo de forma divertida, mas sem fugir da responsabilidade de aprender o conteúdo de química. Ao se trabalhar de forma interdisciplinar com o aluno é possível observar que o discente tem um rendimento satisfatório com as formas alternativas de ensino de química. 
The Dynamics of Forms of Chemical Education Alternatives Providing the Student Creativity

Albstract: Education is undergoing many changes in the course of time, among these changes are the new educational trends known as alternative forms of teaching, where he works in an interdisciplinary way, making a connection with what is taught in the classroom and daily life the student. This work aims to show how the two forms of teaching walking together, the traditionalist way and the alternative form of education through themes linked to water chemistry concepts using comics and theater. It was observed that students understand chemistry concepts through their own creations in comic books, making the process of teaching and learning take a new dimension. Despite the barriers faced by both sides, in the classroom, these alternative forms encouraged the production of its own history in order to instigate creativity, responsibility of the student, working with the other school disciplines and encouraging the student to always read.

Keywords: Alternative forms of education; theater; comic; chemistry teaching.

\section{Referências bibliográficas}

CONDE, T. T. LIMA, M. M. BAY, M. Utilização de Metodologias Alternativas na Formação dos Professores de Biologia no IFRO - Campus Ariquemes. Revista Labirinto, Ano XIII, №18, 2013.

FRANCISCO JUNIOR, W. E. Estratégias de leitura e educação química. Química Nova na Escola, v.32, n. 4, 2010.

LDB - Leis de Diretrizes e Bases da Educação Nacional. Lei no. 9.394, de 20 de dezembro de 1996. D.O.U. de 23 de dezembro de 1996.

PIZARRO, M. V. As Histórias Em Quadrinhos Como Linguagem e Recurso Didático No Ensino De Ciências. In: Anais do VI I Anpec. UFSC: Florianópolis, 2009.

ROSA, D. L. Aplicação de metodologias alternativas para uma aprendizagem significativa no ensino de química. Monografia (Especialização em Ensino na Educação Básica) - Departamento de Educação e Ciências Humanas do Centro Universitário Norte do Espírito Santo da Universidade Federal do Espírito Santo. 97 p. 2012.

SILVA ,M. L. G. TEXEI RA, A. F. RUIZ, M. A. S. A Formação de Conceitos Científicos Através de Concepções Alternativas no Ensino de Química. In: Anais do Congresso AFI RSE, 2006.

SILVA, S. D. SILVA, V. M. SOARES, A. C. O Cinema e os Quadrinhos: Ferramentas Alternativas Para o Ensino de Química. In: Anais do 33 EDEQ. UNIJUI. Ijuí, 2013.

ZLBERMAN, R. A leitura no Brasil: história e instituições. In: LEFFA, V. J.; PEREIRA, A. E. (Org.). O ensino da leitura e produção textual. Pelotas, 1999, p. 39-50. 